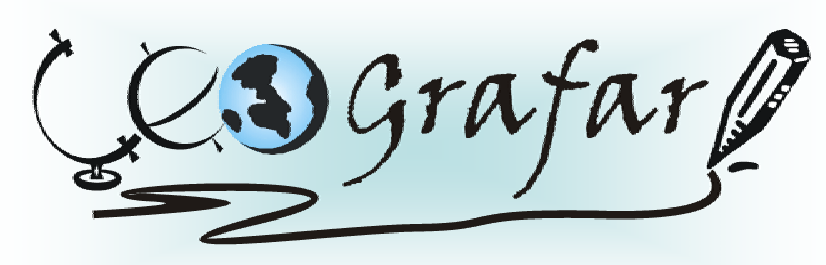

Revista Eletrônica do Programa de Pós-Graduação em Geografia - UFPR

\title{
A INTERNACIONALIZAÇÃO DA ECONOMIA URBANA: UMA ANÁLISE DO SETOR HOTELEIRO DE CURITIBA - PR ${ }^{1}$.
}

\author{
DIANI EIRI CAMILO MOSSATO
}

\begin{abstract}
RESUMO A presença nas cidades de novas atividades de comércio e serviços especializados voltados principalmente à demanda das empresas globais, característica da internacionalização da economia, se apresenta como aspecto significativo para a atual reestruturação do espaço urbano, desencadeando a acentuação do uso seletivo do solo e a emergência de novas centralidades ou centros de consumo de bens e serviços de padrão diferenciado. Neste contexto, o presente estudo se propõe a compreender como esta dinâmica se materializa na cidade de Curitiba, verificando os fatores que contribuíram para a sua efetivação, bem como as principais transformações a ela associadas, em especial a ascensão de uma nova centralidade para a cidade ou de um centro de consumo de bens e serviços com padrão de qualidade internacional, qual seja, o bairro Batel.
\end{abstract}

Palavras-chave: Internacionalização; Curitiba; economia urbana; setor hoteleiro.

\section{THE INTERNATIONALIZATION OF THE URBAN ECONOMY: An analysis of the hoteleiro sector of Curitiba - PR.}

\begin{abstract}
The presence of new activities and specialized commerce directed mainly to the demand of global enterprises, internationalization's economy characteristic, presenting itself as an important aspect for nowadays urban space reconstruction, producing the emphasizing of the selective usage of the soil and the appearing of new distressing centers of goods and services of different patterns. In this context, this study is proposed to get comprehension of how this dynamic is materialized in Curitiba city, verifying the factories that had helped its effectuation, and also the mainly transformations associated to them, specially the coming up of a new center to the city or of a center of distressing of goods and services with international quality pattern that is Batel district. Key words: Internationalization; Curitiba; urban economy; hoteleiro sector.
\end{abstract}

\section{INTRODUÇÃO}

Os anos de 1990 marcaram profundas transformações na economia urbana curitibana. As alterações na dimensão econômica tiveram sua correspondente no âmbito sócio-espacial, pois, a emergência de Curitiba enquanto importante vetor da desconcentração industrial no Brasil corresponde também à aceleração dos fluxos migratórios. No entanto, enquanto o espaço do aglomerado metropolitano é ocupado pelas novas indústrias e pela população - em

\footnotetext{
${ }^{1}$ Texto elaborado com base na Dissertação de Mestrado de mesmo título, apresentada como requisito parcial para a obtenção do Grau de Mestre ao Programa de Pós-Graduação em Geografia, Setor de Ciências da Terra, Universidade Federal do Paraná, orientada pela Prof. ${ }^{a}$ Dr. ${ }^{a}$ Olga L. C. F. Firkowski.

${ }^{2}$ Graduada e Mestranda em Geografia pela Universidade Federal do Paraná. dianieiri@curitiba.org.br
} 
especial aquela sem qualificação para o trabalho - o espaço do seu núcleo se reserva à localização das novas atividades metropolitanas, principalmente o comércio e os serviços especializados e/ou corporativos, e às pessoas a elas associadas.

Boa parte das atividades implantadas em Curitiba a partir deste período, relacionadas à indústria e ao setor de comércio e serviços, é controlada por grupos de atuação mundial, o que configura a internacionalização da sua economia.

A estreita associação entre a reestruturação sócio-econômica e a reestruturação espacial é apontada por muitos autores, entre eles, Soja (1993), Borja e Castells (1997) e De Mattos (2002). Assim, a compreensão de quais alterações a nova dinâmica econômica - com forte caráter de internacionalização - promove no âmbito do espaço urbano de Curitiba é a principal questão discutida, privilegiando a análise das transformações havidas no setor hoteleiro, no período compreendido entre 1990 e meados de 2006.

A escolha pelo setor hoteleiro se justifica uma vez que o mesmo é considerado sensível à internacionalização da economia urbana (BORJA E CASTELLS,1997; SASSEN,1998; DE MATTOS,2004); requisito indispensável à constituição de um nó da economia global (BORJA; CASTELLS, 1997, p. 16), cujas edificações, sobretudo dos recentes hotéis de luxo, figura entre as transformações significativas da nova paisagem urbana (DE MATTOS, 2004, p.185) e sua localização importante para a conformação de sub-centros ou novos centros urbanos (FUENTES E SIERRALTA, 2004).

A escolha por uma atividade do setor de serviços esclarece, ainda, a maneira como se compreende a economia urbana neste texto, que se aproxima muito mais do conceito de "nova economia urbana” de Sassen (1998, p. 18; 21; 75-77), onde a prestação de serviços se apresenta como setor nuclear, dominante e, na qual, as finanças e os serviços especializados figuram como a energia propulsora para a obtenção de lucros.

Embora a extensão das transformações associadas à internacionalização dos diversos setores da economia urbana se materialize pelo Aglomerado Metropolitano ${ }^{3}$, o seu núcleo,

\footnotetext{
${ }^{3}$ Por Aglomerado Metropolitano compreende-se a mancha urbana contígua a Curitiba que se estende pelos municípios de Almirante Tamandaré, Araucária; Campina Grande do Sul; Campo Largo; Campo Magro; Colombo; Fazenda Rio grande; Pinhais; Piraquara; Quatro Barras e São José dos Pinhais.
} 
Curitiba, foi o recorte espacial priorizado, por concentrar a localização dos hotéis ${ }^{4}$, sobretudo, aqueles de bandeira internacional.

Uma vez que as transformações espaciais verificadas para Curitiba se relacionam diretamente com as dimensões econômica e política da cidade, espera-se que as reflexões que aqui se estabelecem, possam, minimamente, contribuir para a compreensão da reestruturação urbana da metrópole, ainda que esta não se tenha concluído.

\section{A COMPETITIVIDADE INTERURBANA E AS ESTRATÉGIAS LOCAIS PARA A ATRAÇÃO DE INVESTIMENTOS}

Indiscutivelmente, Curitiba é hoje uma metrópole conectada ao mundo e com forte presença de capitais internacionais em diversas atividades econômicas, além de ser definida na rede urbana brasileira como metrópole nacional (MOTTA; AJARA, 2001), cuja mancha urbana já extravasou para os municípios vizinhos. Portanto, se os processos da internacionalização estão transformando o papel, a morfologia, o funcionamento e a estrutura das grandes cidades, reforçando seu status de motores geo-econômicos do sistema mundial, como afirmam Fuentes e Sierralta (2004), Cicolella (2005) entre outros, acredita-se que este fenômeno também se faça presente na capital paranaense.

A tentativa de inserir Curitiba entre as cidades privilegiadas pela localização de atividades econômicas internacionais não é recente, porém, verificar os efeitos da internacionalização dos diferentes setores da sua economia o é. Segundo autores como Borja e Castells (1997), os processos decorrentes da internacionalização econômica, modificam a estrutura espacial e social das cidades em todo globo, sendo este o efeito mais direto da articulação entre o global e o local. Porém, tais efeitos sócio-espaciais se efetivam de forma diversa segundo os níveis de desenvolvimento de cada país, o contexto da sua urbanização, sua cultura e suas instituições, ou seja, embora global, o fenômeno da internacionalização da economia não significa homogeneização, mas sim, segundo Benko (2000, p. 68), diferenciação e especialização, dando origem a grandes pólos econômicos, verdadeiros “oásis”.

\footnotetext{
${ }^{4}$ Os hotéis instalados em São José dos Pinhais, município do Aglomerado Metropolitano, não foram incluídos neste estudo uma vez que as localizações dos mesmos se explicam pela proximidade e acessibilidade ao Aeroporto Internacional Afonso Pena.
} 
De Mattos (2002, p. 05) salienta que mediante a diminuição das intervenções e dos investimentos públicos, o capital privado assume o papel de protagonista central do desenvolvimento urbano, devendo as políticas públicas ter como propósito prioritário estabelecer as condições mais favoráveis para a rentabilidade do capital em seus âmbitos territoriais. Uma vez que a cidade é o lócus preferencial para os investimentos das empresas no cenário atual da internacionalização econômica, este espaço de competitividade criado pela globalização induz as cidades a responderem estrategicamente com ações voltadas à atração dos investimentos externos (VÁZQUEZ-BARQUERO, 2000).

O incentivo à instalação de novas empresas e aperfeiçoamento do ambiente econômico a fim de constituir um clima local mais atrativo aos investimentos externos, se apresentaram para a realidade curitibana de forma muito clara, em especial na década de 1990 e podem ser considerados como imprescindíveis às transformações recentes na economia da capital paranaense. Num contexto de competitividade urbana, o histórico de Curitiba enquanto vetor para investimentos internacionais é algo novo e se deve em boa parte à ação do estado, em particular as estratégias de city marketing e a chamada guerra fiscal, acirradas em meio ao fenômeno de desconcentração da indústria no Brasil.

Orientado a incentivar a atratividade por meio da construção de uma imagem forte da cidade, o city marketing figura como elemento vital para a apreensão da realidade atual, mediante o uso intensivo desta estratégia em Curitiba, em especial na década de 1990. Fato, que levou a seguinte afirmação de Sanchez (2001, p. 167): “Tem se, para o Brasil, na cidade de Curitiba, uma referência paradigmática tanto do valor do city marketing incorporado à política quanto dos efeitos do urbanismo-espetáculo, instrumentos que deram a cidade uma inserção nacional e internacional”.

O Paraná também participou ativamente da "guerra fiscal e financeira”, observada no Brasil, em especial na década de 1990, segundo Moura (2003), comprometendo-se de forma direta com estímulos fiscais e financeiros - amparados pela Constituição de 1988 - e físicos para a reestruturação do seu setor industrial, na figura da liberação de responsabilidades fiscais e tributárias por até dez anos; oferta de capitais; doação de terrenos privilegiados e das obras de infra-estrutura no local ${ }^{5}$. Facilidades que se somaram às qualidades intrínsecas ao

\footnotetext{
${ }^{5}$ Prática que Santos (1994, p. 122-123; 130) conceitua como “socialização capitalista”, ou seja, a transferência de recursos públicos para algumas pessoas ou firmas. No intuito de atrair ou manter atividades “de ponta” o Estado utiliza de maneira desigual os recursos públicos na criação ou reabilitação das condições gerais de produção. Dessa forma o Estado se torna, ele próprio um motor das desigualdades.
} 
Aglomerado Metropolitano de Curitiba, que já oferecia um sistema viário e de transporte adequado; proximidade de porto e aeroporto internacional, redes de fibras ópticas, geração, transmissão e distribuição de energia; localização privilegiada em relação ao Mercosul e ao próprio território nacional, entre outras.

Como resultado imediato, verificou-se o fortalecimento da atratividade local, num contexto vivenciado pela economia do país como um todo, em meados da década de 1990, pois, após um período em que enfrentou graves problemas econômicos, a estabilidade monetária tornou o Brasil novamente atraente aos capitais internacionais.

Segundo De Mattos (2002, 2004), a medida que atividades e empresas de caráter global vão sendo implantadas com êxito nas metrópoles em processo de globalização, por si só a sua presença tende a constituir-se também, em verdadeiros ícones da internacionalização da economia urbana. A implantação de unidades produtivas de veículos leves das montadoras Renault (França), Audi-Volks (Alemanha) e Chrysler (EUA) no Aglomerado Metropolitano de Curitiba pode ser considerada como marco recente da internacionalização da economia curitibana, já que dela decorreu uma série de outros empreendimentos internacionais, entre eles as redes hoteleiras de atuação mundial, objeto central do presente trabalho.

A concentração de atividades ligadas a esta nova dimensão da economia urbana, internacionalizada, contribui sobremaneira para as transformações no espaço urbano curitibano, como se verá adiante.

\section{A DINÂMICA DO SETOR HOTELEIRO EM FACE DA INTERNACIONALIZAÇÃO DA ECONOMIA CURITIBANA.}

Enquanto as novas indústrias localizam-se em diferentes espaços do aglomerado metropolitano, em seu núcleo, Curitiba, passam a se instalar "atividades que materializam as novas funções metropolitanas ${ }^{6}$ ” (FIRKOWSKI, 2002, p. 98). Curitiba expande, portanto, na década de 1990, o seu setor de comércio e serviços especializados, onde se verificou forte presença de empresas internacionais.

\footnotetext{
${ }^{6}$ Segundo Merenne-Schoumaker (1998, p. 06), as novas funções metropolitanas englobam não apenas os serviços prestados a população, mas também e principalmente, os serviços prestados às empresas (pesquisa, inovação, marketing, comercialização, comunicação, entre outros), dando um outro conteúdo à metrópole, agora associada à uma grande cidade de serviços, visando a contemplação das demandas das empresas e ao consumo da parcela da população a elas associadas.
} 
Ao se tornar localização de empresas cujas atividades se dão na escala do mundial, credita-se a Curitiba também a possibilidade de tornar-se um forte vetor para o turismo de negócio. Uma certa euforia toma conta da hotelaria local, que tem no momento uma oportunidade de crescimento real. Paralelamente, esta realidade desperta o interesse de cadeias hoteleiras de origens diversas, mediante um possível mercado em expansão. Cabe ressaltar que Curitiba passou a ser vista não apenas como um local para a implantação de novos hotéis, simplesmente, mas, como um mercado aberto para a oferta de novos serviços, ou seja, a demanda não dizia respeito somente ao número de leitos ofertados, mas, principalmente, a diversificação dessa oferta.

Esta gama de possibilidades viria a transformar o setor hoteleiro da capital paranaense, em parte por conta do incremento na instalação de hotéis locais, mas, em especial, mediante a implantação de hotéis de redes nacionais e internacionais. As transformações foram, portanto, muito além do acréscimo na oferta de leitos, alterando também os padrões de qualidade e de localização dos hotéis, segundo as informações aqui analisadas que têm como fontes principais a Secretaria Municipal de Turismo de Curitiba - Viaje Curitiba - e o Instituto de Pesquisa e Planejamento Urbano de Curitiba (IPPUC), além de pesquisa de campo; artigos jornalísticos e acessos aos sites de diversos hotéis, em especial, aqueles das redes nacionais e internacionais. A pesquisa empírica, no entanto, não se restringiu ao período do recorte temporal do estudo, entre os anos de 1990 e 2006, pois, considerações acerca da realidade anterior ao mesmo, foram necessárias para a compreensão do contexto atual.

Em síntese, até o final da década de 1980, o setor hoteleiro de Curitiba era composto por aproximadamente 54 hotéis, destes, basicamente todos de propriedade de empresas locais, sendo que algumas poucas dessas empresas possuíam mais de um estabelecimento nesse setor. A capacidade média por hotel era de aproximadamente 120 leitos e um único hotel instalado até este período aparece entre aqueles atualmente avaliados enquanto "muito confortáveis ${ }^{7}$.

Os dados gerais do período de 1990 a meados de 2006, por sua vez, apontam claramente as mudanças no setor, das quais, pode-se partir da implantação de 76 novos hotéis

\footnotetext{
${ }^{7}$ A classificação de hotéis da Secretaria Municipal de Turismo de Curitiba acompanha os critérios e classificações de empresas nacionais especializadas em turismo. São levados em consideração nestas avaliações tanto os aspectos físicos dos hotéis, como área social, conservação e estrutura, quanto a oferta de lazer e serviços e a localização dos hotéis. Os hotéis localizados em Curitiba são classificados como "simples"; de "médio conforto"; "confortáveis" e "muito confortáveis", sendo que os hotéis ainda não avaliados também foram considerados neste estudo, do qual foram excluídos apenas os motéis.
} 
em Curitiba, o que significa o incremento de 11 mil novos leitos. Ou seja, em cerca de pouco mais de 15 anos a oferta de leitos em hotéis de Curitiba praticamente triplicou, de aproximadamente 6.500 leitos para mais de 17 mil, sendo que, o número médio de leitos por hotel também se elevou para 145 neste período.

Segundo De Mattos (1999), a ampliação da oferta na rede hoteleira, bem como o aumento no número de espaços para conferências e eventos expressam sem dúvida a influência da intensificação da inserção global, que estimula um fluxo permanente de visitantes, em especial, aqueles em viagens de negócio.

O salto qualitativo do setor hoteleiro de Curitiba não se apresenta menos relevante do que o quantitativo. Dos 76 hotéis instalados no período entre 1990 e 2006, 57 já passaram pelo processo de avaliação, sendo que apenas 06 foram classificados como hotéis “simples”, ou seja, cerca de apenas 10\% dos hotéis avaliados. Entre os demais, 26 hotéis foram avaliados como "confortáveis", classificação que pode ser considerada como predominante neste período, pois, supera a marca de 1/3 do total dos hotéis instalados (76) e quase a metade dos hotéis avaliados (57), segundo a Secretaria Municipal do Turismo de Curitiba.

Entre os demais, 20 hotéis são classificados como de "médio conforto", enquanto os outros cinco alcançam o topo da avaliação para os hotéis localizados em Curitiba, classificados como “muito confortáveis”. É importante ressaltar que dos seis hotéis curitibanos classificados como “muito confortáveis", cinco, portanto, se instalaram neste último período de análise, informação que aponta para a mudança no perfil dos hotéis instalados em Curitiba.

É neste período também que a hotelaria local se expande e/ou se organiza, dando origem às redes com atuação regional ou nacional, bem como outras redes nacionais iniciam suas atividades em Curitiba. Os dados do ano de 2006 apontam para a presença em Curitiba de 28 estabelecimentos de redes hoteleiras nacionais, entre elas as redes Mabu; Bourbon; Slaviero; Bristol; Elo; 10 Hotéis; Deville; San Juan; Blue Tree; Transamérica e Lancaster. A maioria dos hotéis das redes nacionais é bem avaliada e possui grande capacidade de acomodação.

Tendo em vista que o objetivo principal deste estudo é a análise das alterações espaciais associadas à internacionalização da economia em Curitiba, com um olhar especial sobre as transformações havidas no setor hoteleiro, então este é o período mais relevante. Nos anos de 1990 é que se verifica a implantação dos primeiros hotéis da rede hoteleira 
internacional, sendo o Parthenon Golden, da rede francesa Accor, o primeiro empreendimento em atividade, localizado no Bairro Batel e inaugurado em 1993. Cabe lembrar, que o interesse de instalação da rede francesa Accor se dá concomitantemente à sinalização de interesse da também francesa Renault, em instalar sua unidade montadora de veículos leves no Aglomerado Metropolitano.

O interesse pela instalação de redes hoteleiras de origem não-local, nacional e/ou internacional, bem como a organização dos hotéis locais e conseqüentemente o surgimento de redes locais com atuação regional, pode ser verificado nos primeiros anos da década de 1990 . Este fato corrobora a afirmação de que o período que se inicia na década de 1990 é um marco para as transformações no setor hoteleiro curitibano, juntamente com as demais alterações verificadas em diversos setores da economia urbana.

Novas formas de investimento para o capital local se fizeram possíveis mediante a associação com as redes hoteleiras de origens diversas, as quais a localização em Curitiba se tornou interessante. Embora, os processos de aquisição e fusão sejam predominantes nos investimentos do setor hoteleiro, a relação entre o capital local e os interesses distantes também se realizou por meio de parcerias, acordos de cooperação, contratos de gestão e franquias, onde as redes hoteleiras respondem principalmente pela administração dos empreendimentos, enquanto sobre os investidores locais recaem o peso dos investimentos e os riscos inerentes ao negócio, sobretudo, a flutuação da demanda e a superoferta de leitos.

O número de hotéis instalados vinculados a redes hoteleiras em menos de duas décadas, de 1990 a 2006, chegou a 37 empreendimentos, destes 20 eram de bandeiras nacionais ${ }^{8}$ e 17 de bandeiras internacionais, número que muito se aproxima da metade dos hotéis instalados neste período, 76 no total. No Quadro 01 observam-se os hotéis investigados em atividade em 2006, por ano de instalação, bem como a porcentagem de instalação dos mesmos em cada um dos períodos, mesma informação para os hotéis das redes nacionais e internacionais.

Até meados de 2006, observava-se em Curitiba a presença de 17 hotéis vinculados a redes internacionais, dos quais a maioria era administrada pela rede francesa Accor (09 hotéis - 53\%), que somam-se aos hotéis da rede inglesa Intercontinental (04 hotéis - 24\%); da rede americana Choice (03 hotéis - 18\%) e da portuguesa Pestana (01 hotel - 05\%). Bem como

\footnotetext{
${ }^{8}$ Oito hotéis que em 2006 contavam com bandeiras de redes nacionais foram instalados no período anterior, de 1970 a 1989, totalizando 28 hotéis desta natureza.
} 
para os hotéis das redes nacionais, os internacionais também apresentam-se no topo da classificação e entre os hotéis com maior número de leitos. Nos Quadros 02 e 03, se pode observar a porcentagem dos hotéis das redes nacionais e internacionais em relação ao total dos hotéis instalados em Curitiba e investigados neste estudo, de acordo com a capacidade e com a classe de conforto dos mesmos.

QUADRO 01 - CURITIBA: HOTÉIS EXISTENTES ATUALMENTE POR ANO DE INSTALAÇÃO, 2006.

\begin{tabular}{|l|l|l|l|l|}
\hline \multicolumn{1}{|c|}{$\begin{array}{c}\text { Período de } \\
\text { Instalação }\end{array}$} & \multicolumn{1}{|c|}{ Até 1989} & De 1990 a 2006 & Não divulgado & \multicolumn{1}{|c|}{ Total } \\
\hline Curitiba (Geral) & $54(39 \%)$ & $76(56 \%)$ & $07(05 \%)$ & $137(100 \%)$ \\
\hline Redes Nacionais & $08(29 \%)$ & $20(71 \%)$ & 00 & $28(100 \%)$ \\
\hline Redes Internacionais & 00 & $17(100 \%)$ & 00 & $17(100 \%)$ \\
\hline
\end{tabular}

Fonte: pesquisa direta. Organização: MOSSATO, D. E. C.

QUADRO 02 - CURITIBA: CAPACIDADE DOS HOTÉIS INSTALADOS, 2006.

\begin{tabular}{|l|l|l|l|l|l|l|l|}
\hline Leitos & Até 50 & $\mathbf{5 1 - 1 0 0}$ & $\mathbf{1 0 1 - 1 5 0}$ & $\mathbf{1 5 1 - 2 0 0}$ & $\begin{array}{c}\text { Superior a } \\
\mathbf{2 0 0}\end{array}$ & $\begin{array}{c}\text { Leitos não } \\
\text { divulgados }\end{array}$ & \multicolumn{1}{|c|}{ Total } \\
\hline Curitiba & 17 & 40 & 27 & 32 & 14 & 07 & 137 \\
\hline Redes Nacionais & 00 & $04(10 \%)$ & $09(33 \%)$ & $10(31 \%)$ & $02(12 \%)$ & 03 & $28(20 \%)$ \\
\hline $\begin{array}{l}\text { Redes } \\
\text { Internacionais }\end{array}$ & 00 & $01(2,5 \%)$ & $03(11 \%)$ & $04(12 \%)$ & $09(64 \%)$ & 00 & $17(12 \%)$ \\
\hline
\end{tabular}

Fonte: pesquisa direta. Organização: MOSSATO, D. E. C.

QUADRO 03 - CURITIBA: HOTÉIS INSTALADOS POR CLASSE DE CONFORTO, 2006.

\begin{tabular}{|l|l|l|l|l|l|l|}
\hline Classificação & \multicolumn{1}{|c|}{$\begin{array}{c}\text { Não } \\
\text { avaliados }\end{array}$} & \multicolumn{1}{|c|}{ Simples } & $\begin{array}{c}\text { Médio } \\
\text { conforto }\end{array}$ & Confortáveis & $\begin{array}{c}\text { Muito } \\
\text { confortáveis }\end{array}$ & Total \\
\hline $\begin{array}{l}\text { Curitiba } \\
\text { (Geral) }\end{array}$ & 41 & 18 & 38 & 34 & 06 & 137 \\
\hline Redes Nacionais & 00 & 00 & $13(34 \%)$ & $13(38 \%)$ & $02(33 \%)$ & $28(20 \%)$ \\
\hline $\begin{array}{l}\text { Redes } \\
\text { Internacionais }\end{array}$ & $04(9 \%)$ & 00 & $02(5 \%)$ & $08(21 \%)$ & $03(50 \%)$ & $17(12 \%)$ \\
\hline
\end{tabular}

Fonte: pesquisa direta. Organização: MOSSATO, D. E. C.

Tomando como exemplo a maior capacidade adotada para os hotéis neste estudo, ou seja, superior a 200 leitos, com 14 empreendimentos entre os investigados, observa-se no Quadro 02 que destes, apenas 03 não pertencem a redes, dos 11 demais, 02 pertencem a redes nacionais e nove hotéis a redes internacionais. Aproximadamente 2/3 dos hotéis com esta capacidade, portanto, estão entre aqueles administrados por redes internacionais, que, se somados aos hotéis das redes nacionais alcançariam 76\% dos estabelecimentos com mais de 200 leitos.

Quando o critério analisado é o padrão de qualidade, os números verificados apresentam proporções também significativas, como apresentado no Quadro 03, pois, entre os 
seis hotéis avaliados como “muito confortáveis”, apenas um não pertence a redes hoteleiras. Dos cinco restantes, dois pertencem a redes nacionais (33\%) e três a redes internacionais (50\%).

Para a classificação logo inferior, os hotéis avaliados como “confortáveis”, esta realidade ainda é bastante relevante. Dos 34 hotéis com esta classificação, 13 (38\%) pertencem a redes nacionais; 08 a redes internacionais (21\%) e apenas os 13 demais não estão relacionados a redes, pouco mais de um terço do total.

Para as redes internacionais, os dados são ainda mais expressivos. Os hotéis desta natureza apresentam-se majoritariamente entre os maiores e mais bem avaliados. São nove entre os 14 com capacidade superior a 200 leitos. Dos 08 demais, 04 possuem entre 151 e 200 leitos; 03 entre 101 e 150 leitos e 01 único, entre 51 e 100 leitos. No total são aproximadamente 3.150 leitos, o que representa uma média de 185 leitos, contra as 166 verificados para as redes nacionais e os 145 leitos no geral do último período.

As informações verificadas até aqui apontam para uma inegável transformação no setor hoteleiro de Curitiba nos últimos anos, sobretudo aquelas relacionadas à presença das cadeias hoteleiras, ao incremento da oferta e alteração do perfil dos hotéis no sentido de uma melhor classificação. Tais informações não refletem, ainda, diretamente, a relação entre estas transformações e possíveis alterações no espaço urbano curitibano. Embora, o impacto da instalação de 76 novos hotéis não possa ser desconsiderado sobre nenhum aspecto.

Por ser este um estudo realizado no âmbito da Geografia, as discussões acerca da alteração da localização dos hotéis exigem uma análise diferenciada - sobretudo acerca daqueles vinculados as redes hoteleiras internacionais e que, portanto, apontam transformações espaciais associadas à internacionalização da economia urbana.

\section{NOVAS CENTRALIDADES: O PRIVILÉGIO DA LOCALIZAÇÃO}

Segundo Villaça (1998, p. 24; 45; 342; 354) entre as possibilidades oferecidas pelo espaço metropolitano, a acessibilidade à infra-estrutura é menos importante que a acessibilidade às localizações, pois as infra-estruturas podem ser reproduzidas, as localizações, não. Portanto, “a produção dos objetos urbanos só pode ser entendida e explicada se forem consideradas suas localizações”. A força mais poderosa, mas, não única, 
agindo sobre a estrutura do espaço é, portanto, a disputa pela apropriação diferenciada das vantagens locacionais.

A localização de uma determinada atividade econômica no espaço urbano não se dá aleatoriamente, mas sim, no intuito da maximização dos lucros, uma das formas pelas quais se manifesta a intencionalidade na escolha da localização, como afirma Santos (1997, p. 267): “os objetos que constituem o espaço geográfico atual são intencionalmente localizados”.

As estratégias de localização das cadeias hoteleiras em Curitiba associam a força estruturadora das vantagens locacionais, com a presença das novas atividades e serviços especializados voltados à demanda das empresas globais e às pessoas a elas relacionadas, fator relevante para as recentes modificações no espaço urbano, segundo De Mattos (2002). Se, em boa parte estas novas atividades e serviços especializados são controlados em Curitiba por empresas de atuação mundial, a reestruturação da cidade está intimamente associada à internacionalização da economia.

A importância do turismo de negócios e eventos para a dinâmica da hotelaria curitibana fortalece a localização dos hotéis enquanto estratégia, pois, para esta vertente do turismo o tempo é sempre um fator preponderante, inclusive o tempo gasto no trânsito, por exemplo. A proximidade do hotel a determinados lugares estratégicos, como aeroportos, ou a facilidade de acesso a esses lugares tornou a localização dos hotéis decisiva.

Entre outros fatores é a acessibilidade que justifica a forte concentração dos hotéis no Centro de Curitiba, sobretudo até 1989, já que dos 54 hotéis instalados até aquele ano, e ainda em atividade em 2006, têm-se 50 localizados no Centro e no seu entorno muito próximo e apenas 04 hotéis em bairros mais distantes, instalados, em especial, as margens das principais rodovias que cortam a cidade. As alterações nos padrões de localização dos hotéis no período preferencial desta análise - 1990/2006 - implicam em transformações no espaço urbano e numa série de novos questionamentos sobre estas alterações. No Quadro 04, observa-se a localização neste período e no período anterior, para que as análises posteriores sejam possíveis.

Com foco nos 76 hotéis instalados entre 1990 e 2006 em Curitiba, o Centro ainda apresenta-se como forte pólo de localização, com 36 instalações. Este número, que se aproxima da metade (47\%) do total de hotéis investigados não permite desconsiderar o Centro enquanto localização preferencial para a hotelaria, percebe-se, no entanto, proporcionalmente, a grande diferença para o período anterior, quando 81\% dos hotéis localizavam-se no Centro. 
QUADRO 04 - CURITIBA: LOCALIZAÇÃO DOS HOTÉIS POR ANO DE INSTALAÇÃO, 2006*

\begin{tabular}{|l|l|l|l|l|l|}
\hline $\begin{array}{l}\text { Período de } \\
\text { Instalação }\end{array}$ & Centro & Batel & Centro Cívico & Outros & Total \\
\hline Até 1989 & $44(81 \%)$ & 00 & 00 & $10(19 \%)$ & $54(100 \%)$ \\
\hline $\begin{array}{l}\text { Entre } 1990 \text { e } \\
2006\end{array}$ & $36(47 \%)$ & $15(20 \%)$ & $05(07 \%)$ & $20(26 \%)$ & $76(100 \%)$ \\
\hline
\end{tabular}

Fonte: pesquisa direta. Organização: MOSSATO, D. E. C.

* 07 hotéis não divulgaram o ano de instalação.

Embora o Centro e outros muito próximos a ele continuem concentrando a grande maioria dos estabelecimentos instalados neste período, é possível afirmar uma dispersão mais acentuada dos hotéis pelo município, já que bairros até então não explorados pela hotelaria são contemplados, entre eles a Cidade Industrial de Curitiba e o Centro Cívico. Apesar de bairros também sem tradição para a hotelaria, como o Bigorrilho e o Alto da XV apresentarem um bom número de hotéis implantados a partir dos anos de 1990 - 03 e 04 hotéis respectivamente - são os quinze estabelecimentos verificados para o Batel que mais despertaram a atenção e o interesse para a investigação.

Compreender a atração que o Batel exerce para a instalação de empreendimentos internacionais, sobretudo no setor de serviços, aqui exemplificado pela localização dos hotéis, exige uma observação mais próxima da realidade deste bairro, bem como considerações acerca da dinâmica que as grandes cidades estão vivenciando, qual seja, a emergência de novas centralidades concorrentes ao Centro tradicional.

O Batel é um dos 75 bairros de Curitiba, localizado numa área limítrofe ao bairro Centro, a Oeste do mesmo, como se verifica na Figura 01. A região central do Batel está a 2.161 metros, em linha reta do marco zero da cidade de Curitiba, na Praça Tiradentes. Em relação à área total de Curitiba, que é de $432,17 \mathrm{~km}^{2}$, o Batel, com seus 1,76 km² representa 0,41\% dessa área, ou seja, menos de meio por cento da área do município (IPPUC, 2006), sendo, portanto, um bairro de pouca extensão territorial.

Segundo o censo demográfico de 2000, o Batel possuía 11.778 habitantes, 0,74\% da população curitibana (1.587.315 habitantes) e 4.171 domicílios, 0,87\% dos domicílios existente em Curitiba (479.341 domicílios). Uma média de 2,82 habitantes por domicílio, número inferior a média verificada para a cidade como um todo que é de 3,31 habitantes por domicílio (IPPUC, 2006). 
FIGURA 01 - CURITIBA (PR) - LOCALIZAÇÃO DA ÁREA DE ESTUDO

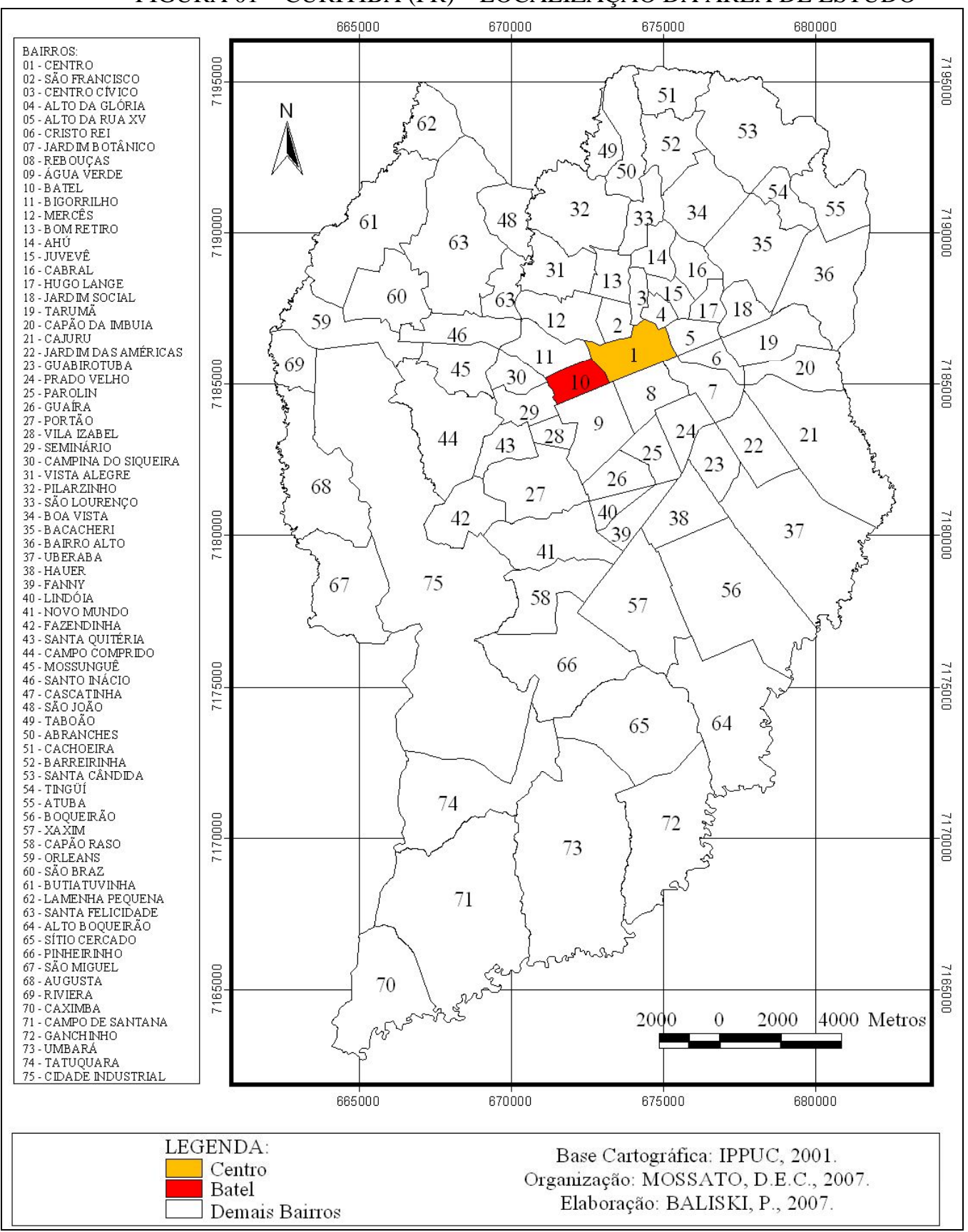

Embora apresentando números mínimos da área total da cidade de Curitiba, bem como da sua população, os dados para o Batel se tornam expressivos quando observadas as informações da realidade econômica deste bairro. O Batel é o $1^{\circ}$ no ranking dos bairros de Curitiba em relação a renda média e também em relação a renda mediana de seus moradores chefes de domicílio, respectivamente 33,91 salários mínimos e 23,18 salários mínimos9. Enquanto a renda média e mediana dos chefes de domicílio para a cidade como um todo era em 2000 de 9,48 salários de renda média e 4,64 salários de mediana. Ainda segundo os dados

\footnotetext{
${ }^{9}$ Salário mínimo referência no ano $2000=\mathrm{R} \$ 151,00$.
} 
do último censo, quase $50 \%$ dos chefes de domicílio no Batel tinha uma renda mensal superior a 20 salários mínimos $^{10}$ (IPPUC, 2006).

Segundo Santos (1994, p. 102), nas metrópoles a dimensão do fenômeno de segregação espacial dá origem a áreas relativamente homogêneas quanto ao nível de renda; à estrutura sócio-profissional; à vocação ao consumo local, etc, que, "induzem a instalação de uma certa tipologia da produção de bens, serviço e comércio”.

Para Moura (2003), a reestruturação econômica e produtiva atual está imbricada à produção do espaço, onde o processo de comercialização e especulação imobiliária daria um novo sentido ao contexto de internacionalização e projeto de construção de um espaço mundial, chamado "espaço de renovação”, ou seja, espaços onde predominam os valores culturais e de consumo dominantes em escala mundial ou espaço codificado, lugar globalizado de consumo e circulação visivelmente seletivos (SÁNCHEZ; MOURA, 2005).

Fundindo-se e confundindo-se com as estratégias do city marketing, que toma cidades inteiras como mercadorias, também fragmentos do espaço urbano passam por processos de transformação e/ou reestruturação, para atender a interesses diferenciados. Embora os setores dominantes tenham sido ao longo do tempo os principais responsáveis pela produção do espaço curitibano, a introdução dos atores globais é recente.

Uma realidade como a evidenciada para o Batel, não passa despercebida aos olhos dos grandes empreendedores, que vêem no bairro a possibilidade de dinamizar seus lucros, ao oferecerem produtos e serviços a uma clientela de alto poder aquisitivo. Contudo, especialmente para a rede hoteleira, a renda ou o padrão de vida dos moradores do Batel são explorados ainda de outras formas, principalmente ao conceder ao próprio espaço do bairro um status privilegiado. Villaça (1998) afirma que quanto mais segregado o espaço, mais fácil à escolha da localização das atividades voltadas à elite.

O Batel não é, portanto, um espaço para muitos. Essa afirmação não se faz verdadeira apenas mediante a pequena dimensão territorial do bairro, mas, em especial pelos custos para a instalação de atividades no local. Custos que, no entanto, não parecem reduzir o interesse pelo bairro, que mediante a crescente concentração de atividades pode ser considerado enquanto centralidade em processo de consolidação.

\footnotetext{
${ }^{10}$ A expressão “elite” é utilizada para designar a parcela de mais alta renda da população e “espaço da elite” como o espaço de moradia, comércio e serviços direcionados a esta população seleta.
} 
A composição das atividades presentes no Batel é bastante diferenciada. Entre os estabelecimentos ativos no bairro em 2005, pode-se perceber a importância que o setor de serviços incorpora, pois, dos 3.329 estabelecimentos existentes no Batel (IPPUC, 2006), mais da metade se dedica à prestação de serviços, 56,59\%, ou seja, 1.884 estabelecimentos. O que é relevante, quando comparado ao índice geral para Curitiba, onde este setor é responsável por cerca de 38,21\% dos estabelecimentos. Por conseguinte o Batel apresenta porcentagens inferiores para os demais setores econômicos em relação à cidade: $28,42 \%$ contra 37,46\% de estabelecimentos que se dedicam ao comércio; 5,8\% contra 9,1\% das indústrias e 9,19\% contra 15,23 entre os estabelecimentos que se dedicam a outras atividades (IPPUC, 2006). A relação de 0,49 estabelecimentos comerciais para cada estabelecimento do setor de serviços demonstra o nível de desenvolvimento da economia do bairro.

Para este contexto, De Mattos (2004, p. 185) afirma que à medida que a terciarização da economia metropolitana foi se intensificando "as atividades e edifícios do setor de serviços foram os que mais incidiram nas mudanças de estrutura, funcionamento e fisionomia da cidade e, portanto, na configuração de uma estrutura policêntrica”. Entre as configurações mais significativas na formação dessa "nova paisagem metropolitana”, as seguintes devem ser destacadas: a) espaços comerciais diversificados e/ou especializados; b) prédios corporativos e conjuntos empresariais; c) hotéis de luxo e alto luxo e locais para realizar feiras internacionais, conferências e grandes eventos e, d) novas configurações de lazer.

Apesar das tardias intervenções urbanas desta natureza em diversas metrópoles, elas configuram a principal expressão simbólica da modernização capitalista globalizada, com impacto no funcionamento e na organização da vida cotidiana da cidade emergente, contribuindo ainda, muitas vezes para reforçar uma parte da metrópole, ou seja, reforçar sua estrutura policêntrica (DE MATTOS, 2004, p. 187-189). Não havendo mais, uma relação espacial direta entre centralidades e entidades geográficas, como até recentemente, quando “centro” e distrito comercial “central” eram sinônimos de uma mesma localização no coração da cidade (SASSEN, 1998, p. 125).

Num bairro com dimensões que não abrangem ao menos $2 \mathrm{Km}^{2}$, a implantação de quinze hotéis - seis deles com capacidade superior a 200 leitos - demanda, sozinha, sensíveis alterações espaciais. Associados aos demais empreendimentos recentes neste bairro, em especial aqueles de natureza internacional, administrativos e de finanças principalmente, e ao setor de comércio, reinventaram a realidade do Batel. 
A tradição de bairro elitizado que acompanha o Batel há quase dois séculos, se mantém, se renova e, sobretudo, se transforma. De local de moradia e indústrias dos barões do mate e depois moradias de políticos e grandes produtores de café, o Batel perde características de bairro residencial ao ver suas casas de arquitetura refinada tornarem-se espaços comerciais nas últimas décadas (FENIANOS, 1997). Num momento posterior, mais recente, a forte presença do setor de serviços torna a alterar profundamente a configuração espacial e funcional do bairro, ainda assim, sem que o mesmo perca seu status de local da elite.

Também o acréscimo no fluxo de pessoas que circula pelo Batel tem implicado em alterações na estrutura do bairro, sobretudo, o fluxo de veículos que por suas ruas transita, uma vez que é assim que se desloca a maioria das pessoas que consomem bens e serviços no local. Villaça (1998, p. 20), destaca o papel fundamental dos deslocamentos do ser humano na estruturação do espaço urbano. Daí vem o poder estruturador das áreas comerciais e de serviços ao atraírem a maior quantidade de deslocamentos, seja de força de trabalho ou de consumidores.

O trânsito de veículos nas ruas do Batel há algum tempo já preocupa os órgãos responsáveis em Curitiba. O prognóstico de que esta realidade num curto espaço de tempo deva se tornar ainda mais complicada, mediante novos empreendimentos no bairro - em especial um grande shopping center - tem levado as autoridades locais a discutirem alternativas para facilitar a circulação.

Enquanto busca alternativas para melhorar o trânsito no Batel, a Prefeitura de Curitiba se vê diante de outro dilema de origem semelhante. Ao mesmo tempo em que as transformações na economia curitibana trazem prosperidade a determinados espaços da cidade, outros se deterioram, caem no abandono e passam a oferecer apenas produtos e serviços populares ou banais, voltados a parcela da população que não apresenta grande poder aquisitivo. O Centro, em Curitiba, como em tantas outras metrópoles, vem vivenciando esse processo nos últimos anos.

A forma seletiva como as atividades se localizam nos diferentes lugares do globo, se repete no interior das metrópoles, privilegiando apenas alguns dos espaços que a compõem. Tais disparidades configuram verdadeiras marcas da geografia econômica mundial e colocam, segundo Moncayo (2004), os impactos territoriais da internacionalização da economia como uma das questões cruciais da agenda do desenvolvimento contemporâneo. 
As especificidades territoriais, elementos essenciais na constituição das vantagens competitivas entre as cidades - como afirma Benko (2000) - torna-se da mesma maneira relevante para a localização das atividades inerentes a contemplação das demandas corporativas, bem como àquelas associadas a um padrão diferenciado de consumo, à escala do espaço intra-urbano, valorizando sobremaneira os locais escolhidos. A efetivação desta realidade ao longo da internacionalização da economia das metrópoles faz emergir a relevância de um determinado bairro e/ou região, em detrimento do tradicional centro da cidade. Em Curitiba, a concentração geográfica do setor de serviços especializados no bairro Batel e entorno próximo, apresenta-se como resultado deste processo.

Não se pretende aqui discutir o abandono ou as alternativas de revitalização de determinados espaços urbanos, mas apontar que novas centralidades se consolidam, em geral, mediante o detrimento dos centros tradicionais. Para a realidade curitibana se pode afirmar, no mínimo, que o Centro não apresenta-se mais como a localização única ou homogênea das principais atividades urbanas, sobretudo, as atividades “emergentes”. Segundo Santos (1994, p. 99), concomitantemente com a modernização de uma fração da cidade ocorre o envelhecimento quase sempre prematuro de outras áreas. A renovação urbana é uma espécie de resposta às necessidades das empresas “mais modernas” e, portanto, tem conseqüências para a economia urbana.

Para além da quantidade de estabelecimentos do setor de serviços no Batel, também o padrão de qualidade oferecido é significativo. Embora este estudo se detenha aos empreendimentos no setor de hotelaria, segundo Firkowski (2004), boa parte do setor de serviços e comércio localizado no Batel é direcionada a uma clientela cujo padrão de consumo é diferenciado, superior. Muitas das atividades ali instaladas, como os hotéis, estão vinculadas a empresas de atuação mundial.

No entanto, nem tudo são rupturas, havendo, portanto, também os processos de transição e até mesmo as continuidades. Fatores que, no entanto, não minimizam a dimensão das transformações, nem negam o processo de consolidação de uma nova centralidade ou centro internacionalizado para a cidade, qual seja, o bairro Batel.

Villaça (1998, p. 321) afirma ainda que a concentração espacial da elite é um aspecto importante para a compreensão das estruturas urbanas, pois funciona como um "motor estruturador” do espaço metropolitano, trazendo para si as atividades e equipamentos urbanos e tornando mais vantajosa esta localização e mais difícil o abandono dessa direção de 
crescimento. Não se pretende aqui, no entanto, discutir a escolha das elites pelo Batel há quase dois séculos, mas, analisar a recente concentração de hotéis, já que é neste bairro que uma grande proporção (20\%) dos hotéis implantados a partir da década de 1990 foi se instalar, um espaço onde até então não se verificava a localização de nenhum empreendimento do setor hoteleiro.

Quando o recorte que se estabelece diz respeito a natureza dos hotéis presentes no Batel, observa-se que a hotelaria que ali se localiza apresenta características muito próprias, tanto acerca do padrão de qualidade, quanto sobre o tamanho dos hotéis. Entre os quinze hotéis localizados no Batel, onze estão entre os avaliados como "confortáveis”, ou seja, praticamente $80 \%$ do total. A predominância dos hotéis “confortáveis" aponta para a concentração da hotelaria com padrão de qualidade superior no Batel. A capacidade de leitos verificada nos hotéis do Batel também é expressiva, pois, entre os quatorze maiores hotéis da cidade, aqueles cuja capacidade é superior a 200 leitos, 06 estão no Batel.

Além do grande número de leitos e padrão de qualidade superior dos hotéis localizados no bairro, o vínculo dos hotéis do Batel às redes hoteleiras nacionais e internacionais é muito significativo (Quadro 05). Entre os hotéis com bandeiras nacionais cinco, dos 28 verificados em Curitiba estão no Batel, ou seja 18\% dos mesmos, número que, embora relevante, nem se aproxima dos dados acerca das redes internacionais, onde, dos 17 hotéis instalados em Curitiba, 08 localizam-se no bairro Batel, 47\%, número que supera os cinco hotéis internacionais localizados no Centro.

QUADRO 05 - CURITIBA: LOCALIZAÇÃO DOS HOTÉIS DAS REDES NACIONAIS E INTERNACIONAIS, 2006

\begin{tabular}{|l|l|l|l|l|l|}
\hline Redes & Centro & Batel & Centro Cívico & Outros & Total \\
\hline Nacionais & $16(57 \%)$ & $05(18 \%)$ & $02(07 \%)$ & $05(18 \%)$ & $28(100 \%)$ \\
\hline Internacionais & $05(29 \%)$ & $08(47 \%)$ & $01(06 \%)$ & $03(18 \%)$ & $17(100 \%)$ \\
\hline
\end{tabular}

Fonte: pesquisa direta. Organização: MOSSATO, D. E. C.

A associação do Batel à hotelaria de qualidade é tão significativa que mesmo hotéis que não se localizam ali, passaram a divulgar sua localização como sendo no bairro. É o caso do hotel da rede Pestana em Curitiba, que apesar de estar localizado no Centro, divulga, como estratégia de marketing, sua localização no Batel. O grupo Pestana, aliás, é o único entre as redes hoteleiras internacionais em atividade em Curitiba - quatro no total - que não possui nenhum estabelecimento no Batel. Das demais, a rede francesa Accor que atua com nove estabelecimentos na cidade de Curitiba, está presente no Batel com quatro hotéis de categorias 
e bandeiras diferentes - Íbis (01 hotel) e Mercure (03 hotéis). Dos quatro hotéis da Intercontinental, um está no Batel, o Holiday Inn Batel, enquanto a totalidade dos hotéis vinculados à rede Choice Hotels está no Batel, três empreendimentos das bandeiras Quality, Radisson e Four Points by Sheraton.

A Figura 02 apresenta informações relevantes, uma vez que se pode observar a localização dos hotéis internacionais em Curitiba, a forte concentração dos hotéis desta natureza no Batel, bem como a tendência de localização dos hotéis internacionais na porção norte da cidade, ou seja, todos numa mesma direção, a partir do Batel.

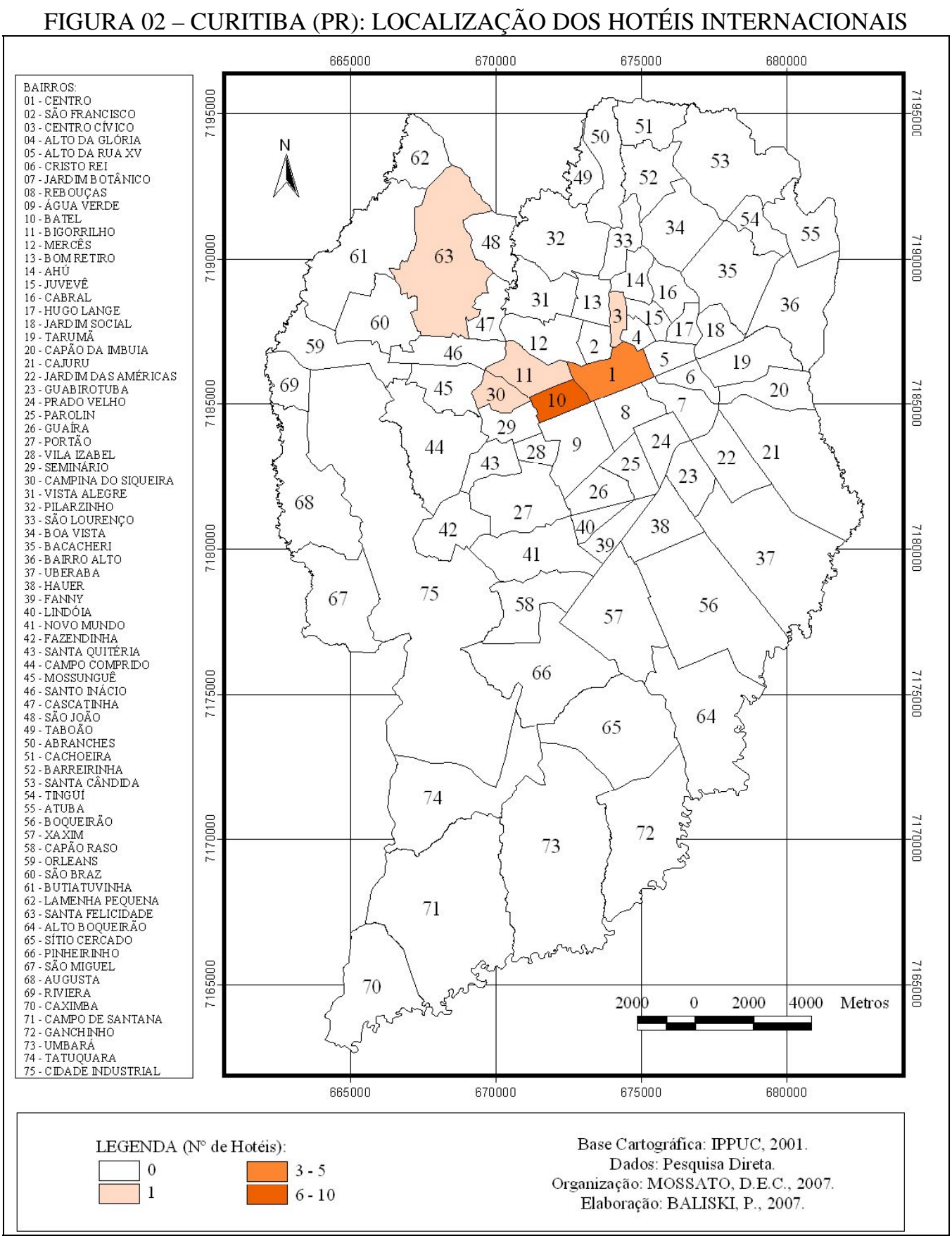


A forte atuação da hotelaria internacional no Batel, controlando oito dos quinze hotéis instalados no bairro, aponta a internacionalização como um processo sócio-econômico e espacial significativo no Batel.

A presença da hotelaria com as características apresentadas anteriormente, somadas as demais atividades que também se concentram nesse bairro, apontam para a emergência do Batel como nova centralidade urbana, concentradora, em particular, das atividades controladas por empresas de atuação global, sendo uma relevante expressão espacial do processo de internacionalização da economia.

É coerente salientar que a localização do hotel, do shopping, do edifício residencial ou de qualquer outro empreendimento não restringe as transformações espaciais ao local da sua instalação, uma vez que todo o espaço urbano ou metropolitano, como é o caso de Curitiba, está inter-relacionado. Segundo Villaça (1998, p. 332), o espaço que se produz e que se consome é muito mais que o do terreno, é o de toda a metrópole, pois ela é uma estrutura e uma estrutura é antes de tudo, um todo.

As transformações, por sua vez, não se resumem a dimensão espacial, mesmo que esta seja a dimensão privilegiada de análise, sendo sentida com diferentes intensidades nas demais dimensões metropolitanas: sócio-econômica, política e cultural. Para o setor hoteleiro, tais alterações se apresentaram de forma muito significativa, ainda que não seja este o momento para discuti-las.

\section{CONSIDERAÇÕES FINAIS}

A análise dos aspectos contemporâneos da reestruturação urbana não é fácil de realizar, como afirma Soja (1993). A dinâmica das alterações não permite que se anunciem resultados que ainda não se pronunciaram definitivamente. Diante dessa realidade, torna-se necessário reafirmar o caráter das discussões que aqui se estabeleceram como reflexões, considerações sobre um processo em curso. Por outro lado, não faria sentido algum aguardar a consolidação das transformações, até porque elas não cessam, ainda que a força motriz que as estimulam seja outra, que não a internacionalização da economia, cuja associação com a reestruturação urbana no Aglomerado Metropolitano de Curitiba foi o foco deste estudo.

Parece também inevitável que a análise das transformações havidas em apenas um setor da economia urbana, o hoteleiro, de certa forma, possa restringir a contribuição da 
pesquisa realizada. No entanto, frente à realidade complexa imposta aos espaços urbano e metropolitano pela nova dimensão econômica, toda e qualquer contribuição deve ser considerada relevante e, é esta certeza que motivou as reflexões realizadas.

Teoricamente, o setor hoteleiro é apontado como sensível à internacionalização da economia e, foi assim também que ele se apresentou mediante a pesquisa empírica. Particularmente para a realidade curitibana, nos anos de 1990, ao mesmo tempo em que o setor hoteleiro se ampliou e se diversificou impulsionado pelas transformações econômicas, em especial, pela instalação no Aglomerado Metropolitano de Curitiba de novas unidades produtivas controladas por empresas de atuação mundial, também, este setor passou a contar com empreendimentos vinculados às multinacionais do setor de serviços.

A localização em Curitiba das atividades econômicas mais significativas reforçou a centralidade da mesma no aglomerado metropolitano, enquanto na dimensão interurbana, Curitiba ampliou a sua conexão com o mundo, mediante a forte presença de capitais internacionais em diversos setores econômicos.

Como as decisões de investimento e localização das empresas de atuação mundial dependem em boa parte dos fatores de atração, ou seja, das vantagens locacionais de determinados espaços, cabe ressaltar a atuação do estado no desencadeamento do processo de internacionalização econômica, em especial, em razão dos incentivos fiscais e das eficientes estratégias de city marketing.

No setor hoteleiro, tanto a demanda diferenciada verificada com a chegada das novas indústrias, representada pelo turismo de negócios, quanto o acirramento da competitividade mediante a implantação em Curitiba de hotéis das grandes cadeias nacionais e internacionais estimularam expressivas mudanças. As alterações não se restringiram aos aspectos quantitativos, à ampliação do setor, já que também o perfil dos hotéis se transformou. Além de mais numerosos e maiores, os hotéis se diversificaram no intuito de atender todo tipo de demanda, seja ela por categorias diferenciadas ou por infra-estrutura, desde o acesso à internet banda larga, até a realização de grandes eventos.

Contudo, a mudança no padrão de localização dos novos hotéis foi a alteração mais relevante para a pesquisa, pois, permitiu reflexões sobre as transformações no espaço urbano. A concentração de hotéis no bairro Batel, sobretudo aqueles com grande número de leitos, com classificação superior e com bandeira das redes nacionais e internacionais, aponta para uma preferência de localização destas atividades no Batel em detrimento do Centro. 
Segundo Villaça (1998, p. 24), “a produção dos objetos urbanos só pode ser entendida e explicada se forem consideradas suas localizações”. Todas e quaisquer relações afirmadas como determinantes para a localização dos hotéis no Batel, ainda não serão as únicas, no entanto, algumas delas devem ser salientadas.

A escolha da localização para a instalação das atividades econômicas é fundamental ao êxito da mesma. Por ser intrinsecamente desigual, o espaço urbano oferece múltiplas possibilidades, entre as quais, algumas são mais relevantes para a implantação de determinadas atividades e indiferentes a outras.

A homogeneidade do Batel como moradia da parcela da população de mais alta renda, atrai para aquele bairro atividades voltadas ao consumo da sua população seleta, entre elas, cadeias de lojas e produtos internacionais. A presença dos hotéis no Batel é singular, pois estes não se direcionam diretamente à população local, são diferentes dos shoppings e hipermercados aos quais, o potencial do mercado local é de suma importância. Ainda assim, o tradicional status do Batel é também desfrutado pela hotelaria e tornou-se tão significativo a ponto de hotéis localizados no Centro informarem, como estratégia de marketing, que se localizam no Batel.

A acessibilidade aos demais espaços da cidade figura também como um entre os aspectos mais relevantes para a localização de empreendimentos da hotelaria. O acesso a partir do Batel a outros importantes pontos da cidade, em especial o aeroporto, centros de convenções ou a administração pública estadual ou municipal, não apresenta dificuldades, ainda que a localização em outros bairros pudesse propiciar melhor acessibilidade. Este aspecto parece não ter sido tomado como elementar, pois, se assim o fosse, ter-se-ia uma outra distribuição destas atividades pela cidade. Se a acessibilidade a outros espaços deixa de ser tão relevante, faz-se crer que realmente emerge no Batel uma nova centralidade, cuja concentração e diversificação das atividades permitem que ali se satisfaça todo tipo de necessidade para o consumo de bens e serviços, não exigindo deslocamentos freqüentes.

A ciência de que não apenas as atividades do setor hoteleiro seguem esta tendência de localização, possibilitou afirmar que a concentração das novas atividades metropolitanas, sobretudo o comércio e os serviços especializados, com forte presença de empresas de caráter internacional no Batel, contribui para a consolidação de uma nova centralidade ou centro internacionalizado para a cidade. Uma vez que o Batel é o espaço da elite curitibana há mais 
de um século, a localização das atividades associadas à internacionalização da economia urbana reforça a segregação espacial verificada em Curitiba.

A dimensão espacial, privilegiada neste estudo, permitiu, portanto, discutir as transformações verificadas no espaço urbano associadas à nova dimensão econômica da metrópole. A continuidade das reflexões, bem como a sua ampliação e aprofundamento, apresentam-se como fundamentais, pois seus resultados estão em aberto: a centralidade do Batel é ainda uma tendência, enquanto se procura alternativas para a revitalização do bairro Centro.

\section{REFERÊNCIAS}

BENKO, Georges. Estrategias de comunicación y marketing urbano. EURE - Revista Latinoamericana de Estudios Urbanos Regionales, Santiago de Chile, v. 26, n. 79, dic, 2000.

BORJA, Jordi; CASTELLS, Manuel. Local y Global. La Gestión de las Ciudades en la Era de la Información. Madrid: Taurus-Pensamiento, 1997.

CICCOLELLA, Pablo. Ciudades del capitalismo global: terra incognitae? Nuevas relaciones económico-territoriales, nuevos territorios metropolitanos: reflexiones partiendo de casos iberoamericanos. In: RIBEIRO, A. C. T.; TAVARES, H. M.; NATAL, J. L. A.; PIQUET, R. P. S. (Orgs). Globalização e Território: ajustes periféricos. Rio de Janeiro: Arquimedes Edições, 2005.

DE MATTOS, Carlos A. Santiago de Chile, globalización y expansión metropolitana: lo que existía sigue existiendo. EURE - Revista Latinoamericana de Estudios Urbanos Regionales, Santiago de Chile, v. 25, n. 76, diciembre, 1999.

. Transformación de las ciudades latinoamericanas. Impactos de la globalización. EURE - Revista Latinoamericana de Estudios Urbanos Regionales, Santiago de Chile, v. 28, n. 85, diciembre, 2002.

. Redes, Nodos e Cidades: Transformação da Metrópole LatinoAmericana. In: RIBEIRO, Luiz Cesar de Queiroz (Org). Metrópoles: entre a coesão e a fragmentação, a cooperação e o conflito. São Paulo: Editora Fundação Perseu Abramo; Rio de Janeiro: FASE, 2004.

FENIANOS, Eduardo Emílio. Batel - Das Charretes aos Topetes. Curitiba: UniverCidade, 1997.

FIRKOWSKI, Olga L. C. F. A Nova Lógica de Localização Industrial no Aglomerado Metropolitano de Curitiba. Revista Paranaense de Desenvolvimento, Curitiba: IPARDES, n. 103, jul./ dez. 2002.

Internacionalização e novos conteúdos de Curitiba. Revista

Paranaense de Desenvolvimento, Curitiba: IPARDES, n. 107, jul./ dez. 2004. 
FUENTES, Luis; SIERRALTA, Carlos. Santiago de Chile, ejemplo de una reestruración capitalista global? EURE - Revista Latinoamericana de Estudios Urbanos Regionales, Santiago de Chile, v. 30, n. 91, diciembre, 2004.

IPPUC. Instituto de Pesquisa e Planejamento Urbano de Curitiba. <http://www.ippuc.org.br $>$ acessos de julho de 2005 à dezembro de 2006.

MERENNE-SCHOUMAKER, Bernadette. A metropolização - um dado novo? In: BARATA-SALGUEIRO, Teresa (coord.). Globalização e reestruturação urbana. Lisboa: Centro de Estudos Geográficos da Universidade de Lisboa, 1998.

MONCAYO, Edgard. El debate sobre la convergencia económica internacional e interregional: enfoques teóricos y evidencia empírica. EURE - Revista Latinoamericana de Estudios Urbanos Regionales, Santiago de Chile, v. 30, n. 90, septiembre, 2004.

MOTTA, Diana Meirelles; AJARA, Cesar. Configuração da Rede Urbana do Brasil. Revista Paranaense de Desenvolvimento, Curitiba: IPARDES, n. 100, jan./ jun. 2001.

MOURA, Rosa. Inversiones Urbanas en el contexto de la competitividad y globalización: los eventos en Curitiba. EURE - Revista Latinoamericana de Estudios Urbanos Regionales, Santiago de Chile, v. 29, n. 86, mayo, 2003.

PMC. Prefeitura Municipal de Curitiba/Secretaria Municipal do Turismo - Viaje Curitiba <http://www.curitiba.pr.gov.br/viajecuritiba> acessos de julho de 2005 à novembro de 2006.

SÁNCHEZ, Fernanda. A (in)sustentabilidade das cidades-vitrine. In: ACSELRAND, Henri (org). A duração das cidades: sustentabilidade e risco nas políticas urbanas. Rio de Janeiro: DP\&A, 2001.

SÁNCHEZ, Fernanda; MOURA, Rosa. Ciudades-modelo: estrategias convergentes para su difusión internacional. EURE - Revista Latinoamericana de Estudios Urbanos Regionales, Santiago de Chile, v. 31, n. 93, agosto, 2005.

SANTOS, Milton. Por Uma Economia Política da Cidade: O Caso de São Paulo. São Paulo: Hucitec, 1994.

Hucitec. São Paulo, 1997.

A Natureza do Espaço. Técnica e Tempo. Razão e Emoção. Editora

SASSEN, Saskia. As cidades na economia mundial. Tradução Carlos Eugênio Marcondes de Moura. São Paulo: Studio Nobel, 1998.

SOJA, Edward W. Geografias pós-modernas: a reafirmação do espaço na teoria social. Tradução Vera Ribeiro; revisão técnica Bertha Becker e Lia Machado. Rio de Janeiro: Jorge Zahar Ed. 1993.

VÁZQUEZ-BARQUERO, Antonio. Desarrollo endógeno y globalización. EURE - Revista Latinoamericana de Estudios Urbanos Regionales, Santiago de Chile, v. 26, n. 79, diciembre, 2000.

VILLAÇA, Flávio. Espaço intra-urbano no Brasil. São Paulo: Studio Nobel; FAPESP: Lincoln Institute, 1998. 